\title{
PIBID CIÊNCIAS E BIOLOGIA: PERCEPÇÕES SOBRE CURRÍCULOS, EDUCAÇÃO E PROJETO ESCOLA SEM PARTIDO
}

\author{
Alexandre Luiz Polizel ${ }^{1}$ \\ Moises Alves de Oliveira ${ }^{2}$ \\ Marinez Meneghello Passos ${ }^{3}$
}

\begin{abstract}
Resumo: este trabalho tem por objetivo levantar considerações sobre a questão: "Quais são as percepções discursivas dos Pibidianos de Ciências e Biologia sobre o projeto Escola sem Partido - EsP e seus efeitos no que tocam os currículos, educação e o chão da escola?”.Foram utilizados questionários semiestruturados, aos Pibidianos do subprojeto Ciências e Biologia da Universidade Estadual de Maringá, situada em Maringá. As questões foram organizadas em dois blocos discursivos, referentes: a) às compreensões dos Pibidianos sobre currículos, educação e ensino; e, b) às percepções sobre o projeto Escola sem Partido e seus efeitos.Utilizou-se da análise de discurso sob inspiração arqueológica Foucaultiana, para a análise das discursividades dos estudantes.
\end{abstract}

Palavras-chave: Percepções; Ciências e Biologia; Pibid; Escola sem Partido.

\section{PIBID sciences and Biology: perceptions on curriculums, education and design school without party}

\begin{abstract}
This paper aims to consider the question: "What are the discursive perceptions of the Pibidians of Science and Biology about the project School without Party - SwP and its effects on curriculum, education and the school floor?". For this were used semi-structured questionnaires, to the Pibidians of the Science and Biology subproject of the State University of Maringá, located in Maringá. The questions were organized in two discursive blocks, referring to: a) the Pibidians' understandings on curricula, education and teaching; and, b) perceptions about the project without Party School and its effects. The analysis of discourse under Foucaultian archaeological inspiration was used for the analysis of students' discourses,
\end{abstract}

Keywords: Perceptions; Science and Biology; Pibid; School without Party.

\footnotetext{
Universidade Estadual de Londrina. (alexandre_polizel@hotmail.com)

${ }^{2}$ Universidade Estadual de Londrina. (moises@uel.br)

${ }^{3}$ Universidade Estadual de Londrina. (marinezmp@sercomtel.com.br)
}

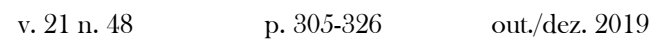




\section{NOTAS INTRODUTÓRIAS}

Percepções: Modos de ver, compreender, analisar, assimilar, julgar... Não obstante, arriscamos dizer que são os modos como se afeta e se deixa afetar por determinado discurso. São os encontros discursivos e dos corpos nas micropolíticas e, como estes se balizam e derivam-se. Nesse manuscrito, nos interessamos pelo encontro de dois desses corpos: a) Os Pibidianos, ou seja, os participantes do Programa Institucional de Bolsas de Iniciação à Docência Pibid, subprojeto Ciências e Biologia; e, b) Projeto Escola sem Partido - EsP.

Apresentemos primeiramente os Pibidianos e o Pibid. O Programa Institucional de Bolsas de Iniciação à Docência consiste em um programa de incentivo à docência, tendo como meta a promoção de melhorias no campo da Educação Básica do País. No programa atuam estudantes de licenciaturas - por meio de uma parceria entre escolas da educação básica da rede pública de ensino, instituições de ensino superior inscritas no projeto - no caso deste artigo focamos nos Pibidianos (esses estudantes) que participam das atividades. Este programa é regulado pela Coordenação de Aperfeiçoamento de Pessoal de Nível Superior - CAPES a partir de 2007 (CAPES, 2015). Nosso enfoque neste corpo textual será como os Pibidianos veiculam e (re)produzem, enunciados que habitam os contemporâneos (anti)movimentos ${ }^{4}$ articulados aos projetos de escola "sem partido", tomando como limite de observação os espaços discursivos.

Evidencia-se que o PIBID consiste em um espaço institucionalizado de práticas, de experimentações, de produções de realidades e de verdades (RIVELINI-SILVA; OLIVEIRA, 2016). Espaço de constituição de si e dos outros, de normalização e de desvios, de reiterar dispositivos ${ }^{5}$ ou de deslocá-los, de exercer a manutenção do espaço ou da produção de espaços outros. Espaço

\footnotetext{
${ }^{4}$ Pontuamos a utilização do termo (anti)movimento, considerando: a) O Escola sem Partido consiste-se em um movimento à medida que coloca atores sociais - humanos e não humanos - em uma rede de relações, que articula-se e desarticula outros coletivos discursiva e não discursivamente; b) Todavia, este consiste também em um "antimovimento" visto que a característica dos movimentos sociais é a definição de um conjunto de estruturações organizacionais, bem como estratégias políticas, que veiculam e reivindicam pautas de populações minoritárias afim de produção de resistência - aspecto ao qual certamente o Escola sem Partido não se encaixa.

"Compreende-se um dispositivo como uma rede de relações de poder-saber-verdade, constituída por elementos heterogêneos, discursivos e não discursivos. Rivelini-Silva e Oliveira (2006) discorrem acerca da composição do Pibid como uma rede heterogênea de relações em que se inserem os Pibids, não referindo-se a um Pibid específico, mas ao dispositivo Pibid.
} 
de múltiplas significações que permitem que os sujeitos constituam aos poucos suas singularidades.

Contudo, este Pibid-espaço também pode ser olhado como um dispositivo (RIVELINI-SILVA; OLIVEIRA, 2016). Se temos esse olhar aportado em Michel Foucault (2016; 2013), ao considerar o Pibid como um dispositivo o ponderamos como sendo um espaço regulador de relações,

[...] um conjunto decididamente heterogêneo que engloba discursos, instituições, organizações arquitetônicas, decisões regulamentares, leis, medidas administrativas, enunciados científicos, proposições filosóficas, morais, filantrópicas. Em suma, o dito e o não dito são elementos do dispositivo. $\mathrm{O}$ dispositivo é a rede que se pode estabelecer entre esses elementos (FOUCAULT, 2016, p. 364).

Desta forma o Pibid consiste em um espaço regulado, controlado, organizado, com objetivos pedagógicos traçados na ordem do discurso. Exercese disciplinamento e controle neste espaço, pedagogizando corpos sob a atuação do dispositivo Pibid. Entretanto, Rivelini-Silva e Oliveira (2016) chamam-nos a atenção para este espaço institucionalizado também como um espaço heterotópico de modo, que mesmo institucionalizado, o espaço constantemente se desloca e, no arraste, produz um espaço outro de atuação, ampliando-se e compactando-se aos fluxos que abarcam diferentes discursos formativos e múltiplas constituições dos sujeitos. O que pretendemos aqui é evidenciar que tal espaço é um espaço regulado, de disciplina e de controle, mas que constantemente é vazado e permite a abertura de linhas de fuga, efêmeras, rápidas, todavia potentes.

Nosso segundo alvo de inquietações consiste nos (anti)movimentos sociais que elaboram e buscam o estabelecimento do chamado Projeto Escola sem Partido. Esse Projeto insurge como (anti)movimento social em 2004, sob a organização do advogado paulistano Miguel Nagib. Aquele emergir foi - à época - inexpressivo, consistindo de agrupamentos de estudantes, pais e professores que conclamavam uma reestruturação educacional tendo como pautas: a) "desinfetar" as escolas públicas, que seriam máquinas contaminadas de doutrinação ideológica; b) revisionismo da liberdade de ensinar e, consequentemente, de aprender; e, c) o direito dos pais de dar a seus filhos a educação moral e religiosa de acordo com suas conviç̧ões (CARA, 2016). 
O (anti)movimento obteve pouca repercussão naquele momento, visto aparentar um modelo de interdição e assepsia pouco relevante e até absurdo à comunidade docente e discente que não comungava de seus ideais.

No entanto, o (anti)movimento permaneceu latente e se reorganizou na forma do Projeto de Lei - PL, proposto pela primeira vez em 2014 na Assembleia Legislativa do Rio de Janeiro, por um Deputado Estadual vinculado ao Partido Social Cristão - PSC/RJ. A espetacularização do projeto torna-se tamanha que o idealizador do (anti)movimento EsP disponibiliza em seu site modelos de projetos estaduais e municipais para que estas proposições sejam disseminadas no âmbito legislativo. Sob tais (anti)movimentos, o Projeto de Lei ${ }^{6}$ é apresentado na Câmara Nacional e no Senado, atualmente também firmado em Comissão Especial da Câmara dos Deputados, passando a ser utilizado como palanque eleitoral de candidatos que ditam-se - autorizados por um emergente e culturalmente vascularizado discurso moral - de "conservadores", sendo o maior número de proponentes ligado à bancada religiosa. Dos 19 proponentes do Projeto, 11 estão ligados a alguma igreja (RATIER, 2016).

Amplamente criticado pela Organização das Nações Unidas (ONU), por professores especialistas em educação, juristas e pela sociedade civil, sobre seus efeitos e (in)constitucionalidade, o projeto vem ganhando força (CARVALHO; POLIZEL; MAIO, 2017), desconsiderando as ponderações da ONU.

Assim, interessamo-nos pelas enunciações veiculadas pelos Pibidianos. Nosso interesse por estas vozes foi fortuito. Trata-se do que os antropólogos chamam de representatividade (FONSECA, 1999), ou seja, o universo simbólico, as questões de interesse a serem compreendidas emergem no encontro. Os alunos estavam lá. Participavam do espaço de formação inicialcontinuada estabelecido pelo currículo oficial de seu curso (no caso de nossos sujeitos ouvidos do curso de Ciências Biológicas), do espaço Pibid e de escolas da rede pública. Tornaram-se interlocutores para nós na medida em que

\footnotetext{
${ }^{6}$ Os Projetos de Lei que correm na Câmara dos deputados com a mesma temática são diversos, contudo se popularizaram o PL 867/2015 sob autoria do deputado Izalci, disponível em: <http://www.camara.gov.br/sileg/integras/1317168.pdf>. - Acesso em: 23 de julho de 2017. E no senado 193/2016 disponível em: <https:/www12.senado.leg.br/ecidadania/visualizacaomateria?id=125666> Acesso em 23 de julho de 2017. Ambos projetos encontram-se arquivados, todavia uma nova versão deste foi apresentada pela atual Deputada Federal Bia Kicis (PSL-DF) PL 246/2019 - projeto com intensificação nas políticas de vigia, denuncia, e proibição de conteúdos estruturantes -, disponível em: <https://www.camara.leg.br/proposicoesWeb/prop_mostrarintegra?codteor=1707037\&filename=PL+246/20 1>. Entre inúmeros projetos que percorrem a nível estadual e municipal. Sendo assim e visto que todos os projetos dispõem do mesmo documento molde, trataremos neste trabalho o Projeto de Lei Escola sem Partido, apenas como PL - a fim de abarcar todos.
} 
percebemos suas funções na ligação das redes destes três espaços, hibridizandoos e forçando seu deslocamento. Por acreditarmos que estes apresentam uma formação inicial-continuada híbrida e de arrastes, nos interessamos por ouvir e localizar seus/suas enunciados/discursividades.

Nosso objetivo neste manuscrito é fazer uma análise dos encontros discursivos da Escola sem Partido no espaço do Pibid Ciências e Biologia nos perguntando: "Quais são as percepções discursivas dos Pibidianos sobre o projeto EsP e seus efeitos no que tocam os currículos, educação e o chão da escola?". Assim, organizamos este trabalho em três eixos: a) nossos instrumentais de registro de percepções e análise destas; b) as discursividades sobre currículos, educação e ensinos que tocam os Pibidianos; e, c) as percepções sobre o projeto EsP e seus efeitos.

\section{PERCURSOS METODOLÓGICOS}

\section{Instrumentos de Pesquisa}

Ao realizarmos os registros, o fizemos em um lugar e de uma forma específica. Nosso lugar-discurso eleito para realizar esta investigação com os integrantes do Programa Institucional de Bolsas de Iniciação à Docência, subprojeto Ciências e Biologia da Universidade Estadual de Maringá.

A iniciativa deu-se por um Pibidiano. Inquieto com as movimentações do projeto EsP, solicitou que uma das reuniões semanais fosse destinada à discussão de tal temática. $\mathrm{O}$ encontro foi agendado para o mês de novembro de 2016, sendo que o Pibid naquele momento contava com 20 integrantes, dois coordenadores de subprojeto, duas professoras supervisoras atuantes na rede estadual de educação do estado do Paraná e 20 alunos/bolsistas. Antes de iniciado o debate, foi elaborado e aplicado um questionário contendo 9 questões apenas aos Pibidianos, considerando que qualquer indagação discursiva abarca intencionalidades, no que toca às respostas que em seguida foram enunciadas. As perguntas consistiram em:

1. O que você compreende por Educar e Ensinar?

2. O que você entende por currículo? Já discutiu sobre currículos? Em qual(is) espaço(s)? Quais efeitos você acredita que o currículo tem no espaço escolar? 
3. O que sabe sobre o Projeto Escola sem Partido?

4. Quais efeitos o projeto causaria na educação em geral e no ensino de biologia?

5. Você acha possível algum tipo educação neutra? Como seria e/ou por quê?

6. Este projeto teria efeitos para a democracia e para a cidadania? Você acredita que ele atende aos princípios da LDB? Justifique sua resposta mesmo se não souber opinar.

7. Para você, qual a relação entre liberdade de ensinar e liberdade de expressão?

8. Em sua opinião, a educação escolar deve atender a valores religiosos e morais de cada família? Como isso interferiria na vida de cada estudante?

9. Em tempos de identidade, diferença e diversidade, quais os efeitos do Projeto de Lei?

Estas questões foram organizadas a fim de se estabelecer dois blocos de análise, sendo: a) Questões destinadas às compreensões que os Pibidianos apresentam sobre currículos, educação e ensino - bloco composto pelas questões 1, 2, 5 e 8; e b) Percepções sobre o projeto EsP - bloco composto pelas questões 3, 4, 6 e 9. A questão 7 consistiu em uma questão guia.

A questão 7 surge como guia, de modo que o (anti)movimento EsP pontua que as "doutrinações ideológicas" dão-se devido aos abusos da liberdade de ensinar, que devem ser revisados e suprimidos da LDB. Chega-se ao comparativo sobre o uso da liberdade de ensinar como possível causador de Síndrome de Estocolmo ${ }^{7}$ nos estudantes, de modo que estes ao serem violentados em sua moralidade pelos "professores doutrinadores" se apaixonam

\footnotetext{
' Evidencia-se que constantemente os mobilizadores do (anti)movimento EsP levantam uma relação direta ao fato de estudantes que se posicionam contra o projeto estão em condição de Síndrome de Estocolmo. A Síndrome de Estocolmo consiste em um estado psicológico em que determinado indivíduo que foi submetido a processos de intimidação e de violações passa a desenvolver afetos - amorosos e de amizades - ao seu violador. Neste sentido, ao trazer esta discursividade a cena, os idealizadores do (anti)movimento EsP posicionam estudantes como em condições de distúrbios mentais e, assim, deslegitimam suas reivindicações contrárias ao projeto educacional EsP - via discursos do campo de saber da psicologia, colocando em cheque a sanidade mental dos estudantes.
} 
por eles e os defendem. Devido a isto, a liberdade de ensinar deve ser suprimida para uma liberdade de cátedra normatizada e a liberdade de expressão não pode ter espaço na atuação do professorado quando dentro do âmbito escolar (CARVALHO; POLIZEL; MAIO, 2017; PENNA, 2017; MATTOS et al., 2017; RATIER, 2016; CARA, 2016; XIMENES, 2016). Vemos que esta, então, é uma ponte entre as questões de educação, ensino e currículo no que se refere as percepções da formação inicial no espaço do Pibid.

\section{Integrantes da investigação}

Foi realizada a aplicação dos questionários a treze Pibidianos,panticipantes da investigação. Estes foram identificados com a letra $\mathbf{P}$ seguida de um número algébrico, de acordo com a ordem de entrega do questionário respondido, sendo organizados de acordo com o Quadro 1:

Quadro 1. Identificações de Pibidianos que responderam aos questionários

\begin{tabular}{|c|c|c|c|c|c|}
\hline PIBIDIANO & GÊNERO & IDADE & RELIGIÃO & $\begin{array}{c}\text { ANO DA } \\
\text { GRADUAÇÃO }\end{array}$ & $\begin{array}{c}\text { TEMPO } \\
\text { NO PIBID }\end{array}$ \\
\hline $\mathrm{P}_{1}$ & FEMININO & 20 ANOS & CATÓLICA & $3^{\circ}$ ANO & 5 MESES \\
\hline $\mathrm{P}_{2}$ & FEMININO & 23 ANOS & CATÓLICA & $5^{\circ}$ ANO & 2 ANOS \\
\hline$P_{3}$ & MASCULINO & 21 ANOS & $\begin{array}{c}\text { NÃO } \\
\text { INDICADO }\end{array}$ & $5^{\circ}$ ANO & 5 MESES \\
\hline$P_{4}$ & MASCULINO & 21 ANOS & ATEÍSTA & $4^{\circ}$ ANO & 2 ANOS \\
\hline$P_{5}$ & FEMININO & 20 ANOS & CATÓLICA & $3^{\circ}$ ANO & 1 ANO \\
\hline$P_{6}$ & FEMININO & 23 ANOS & CATÓLICA & $3^{\circ}$ ANO & 3 ANOS \\
\hline$P_{7}$ & FEMININO & 20 ANOS & ADVENTISTA & $3^{\circ}$ ANO & 3 MESES \\
\hline$P_{8}$ & MASCULINO & 24 ANOS & CATÓLICO & $5^{\circ}$ ANO & 3 ANOS \\
\hline$P_{9}$ & FEMININO & 19 ANOS & CATÓLICA & $2^{\circ}$ ANO & 4 MESES \\
\hline$P_{10}$ & FEMININO & 22 ANOS & NÃO POSSUI & $5^{\circ}$ ANO & 4 ANOS \\
\hline$P_{11}$ & FEMININO & 23 ANOS & CATÓLICA & $4^{\circ}$ ANO & 4 ANOS \\
\hline$P_{12}$ & FEMININO & 20 ANOS & CATÓLICA & $4^{\circ}$ ANO & 1 ANO \\
\hline$P_{13}$ & FEMININO & 22 ANOS & EVANGÉLICA & $5^{\circ}$ ANO & 3 ANOS \\
\hline
\end{tabular}

Fonte: Acervo pessoal 
Os questionários foram agrupados de acordo com o perfil do Pibidiano que o respondeu, sendo possível o estabelecimento de cinco grupos: 1) Pibidiano que não havia cursado estágio supervisionado - ES em ensino de Ciências e Biologia e atuava a menos de um ano no Pibid ( $\left.\mathbf{P}_{9}\right)$; 2) Pibidianos que estavam cursando o ES em Ciências e atuavam há menos de um ano no Pibid $\left(\mathrm{P}_{1}\right.$ e $\left.\mathrm{P}_{7}\right)$; 3) Pibidianos que estavam cursando o $\mathrm{ES}$ em Ciências e atuava a mais de um ano no Pibid $\left(\mathbf{P}_{s}\right.$ e $\left.\mathbf{P}_{6}\right)$; 4) Pibidiano que já havia cursado ES em Ciências e em Biologia e atuava há menos de 1 ano no $\operatorname{Pibid}\left(\mathrm{P}_{3}\right)$; e 5) Pibidianos que já haviam cursado ES em Ciências e em Biologia e atuavam há mais de um ano no $\operatorname{Pibid}\left(\mathbf{P}_{2}, \mathbf{P}_{4}, \mathbf{P}_{8}, \mathbf{P}_{10}, \mathbf{P}_{11}, \mathbf{P}_{12}, \mathbf{P}_{13}\right)$.

\section{Movimentações analíticas}

Para análise das respostas, inclinamo-nos ao uso da análise de discurso com inspiração nas teorizações foucaultianas (FOUCAULT, 2016; 2014; 2008; 2000), considerando que a derivação dos regimes de verdade é proveniente de enunciações e enunciados que apresentam condições de surgimento e de manutenção, sendo esses constantemente reiterados ou negociados, de acordo com as relações, associações, instituições e pedagogias às quais os sujeitos têm contato.

Em um primeiro movimento analisamos os discursos ${ }^{8}$ de cada sujeito participante e, de acordo com suas consonâncias e dissonâncias foi possível agrupá-las no que Foucault (2000) chama de pontos de similitude, que nos permite olhar para as similitudes mais sutis nos enunciados. Essa organização, bem como as respostas analisadas se dão sob uma perspectiva de que essas similitudes discursivas dão-se em determinada contingencia, alinhada a um regime de verdade contingencial. Os regimes de verdade não são estáticos, mas a todo o momento estão se (re)(des)criando, destarte, estes pontos de similitude são pontos de encontro das enunciações que os Pibidianos nos trazem, que em

\footnotetext{
${ }^{8}$ Os discursos para Michel Foucault (2008; 2014) consistem em modos de constituição de regimes de verdades, ou seja, modos de conceber conhecimento acerca das coisas. Os discursos nesse sentido tem um regime de produção, que é controlado e regulado, seleciona o que se encontra ou não na ordem do discurso por mecanismos de inclusão e exclusão (via interdição, segregação e estatuto de verdade). Neste sentido é possível utilizar o discurso como um fio condutor, para compreender os modos de constituição de representações culturais e concepção de realidade, via analise dos discursos em circulação; ou, compreender via desconstrução discursiva suas condições de formação. Optamos nesse manuscrito pelo enfoque nos discursos que são postos em circulação pelos Pibidianos, e assim os modos de instauração de representações culturais acerca do vivido.
} 
nossa leitura, neste momento, convergem ou divergem em agrupamentos distintos.

Aqui consideramos o Pibid como um espaço no qual as discursividades de estudantes de licenciatura em Ciências Biológicas encontravam-se em trânsito. Não temos por objetivo criar uma unidade identitária, mas sim apresentar multiplicidades discursivas que nos foram enunciados nesta intervenção, agrupadas de acordo com suas similitudes de operações. Este espaço-Pibid permitia aos estudantes intervenções em duas escolas estaduais locadas no município de Maringá tendo como público alvo estudantes dos anos finais do Ensino Fundamental. As ações dos Pibidianos eram múltiplas, de modo que demarcamos: a) Revisão de documentos oficiais da escola como Projeto político pedagógico, Regimento Interno, cadernetas escolares, pastas de registro; b) Organização de laboratório de ciências e informática, bem como produção de inventários referente aos materiais disponíveis ao professorado neste local; c) Intervenções com oficinas e minicursos de temáticas interdisciplinares como "meio ambiente", "sexualidades", "sociobiologia", "filosofia da biologia", entre outros; d) Instauração de clube de ciências e sala de apoio em contraturno; e)Assumir frentes didáticas como "professores regentes" e fornecer apoio a professora supervisora do projeto; f) Escrita técnica e cientifica e divulgação de conhecimento no entorno de educação, ensino e formação de professores de ciências e biologias.

O Pibid subprojeto Ciências e Biologia da Universidade Estadual de Maringá tem como perspectiva norteadora o ensino por investigação, todavia abre espaço para múltiplas perspectivas de ensino, na qual os Pibidianos são permitidos a intervir com os referenciais que mais os inspiram, sendo sempre voltados a perspectivas (pós)críticas de ensino. Reiteramos que nosso objetivo consiste na apresentação de discursividades que carregam consigo as percepções dos Pibidianos neste momento de intervenção.

\section{COMPREENSÕES DE CURRÍCULOS, EDUCAÇÃO E ENSINO}

No cenário brasileiro contemporâneo, os documentos oficiais têm sido revisados de modo a levantar questionamentos sobre a legitimidade das novas reformas, bem como o comparativo destes com retrocessos. Vemos múltiplas confusões no que concerne às funcionalidades dos documentos oficiais, sobre $o$ que é um currículo e até mesmo vemos reemergir a dicotomia entre ensino e educação. Percepções que deslocam consideravelmente a atuação do 
professorado no "chão da escola" e em outros espaços educativos. Nos discursos dos Pibidianos evidenciamos três pontos de similitude no que tocaaos seus olhares sobre os currículos: a) Referiam-se ao currículo como um documento norteador, seja documento oficial ou planejamento, que prescreve, estabelece e delimita o que deve ser cumprido no processo formativo $\left(\mathrm{P}_{2}, \mathrm{P}_{4}, \mathrm{P}_{6}\right.$, $\left.\mathrm{P}_{7}, \mathrm{P}_{10}\right)$; b) Compreendiam o currículo como um conjunto de conteúdos organizados e veiculados no espaço escolar, estando ou não vinculado a uma disciplina, que toca a formação de um sujeito $\left(\mathrm{P}_{3}, \mathrm{P}_{8}, \mathrm{P}_{11}, \mathrm{P}_{12}, \mathrm{P}_{13}\right)$; e, c) Currículo como prescrição de si, trajetória de vida, documento que indica percurso formativo $\left(\mathrm{P}_{1}, \mathrm{P}_{9}\right)$. $\mathrm{O}$ Pibidiano $\left(\mathrm{P}_{5}\right)$ indicou que não compreende nada. $\mathrm{A}$ elaboração de tais pontos similitudes discursivos em seus relatos, encontrava-se atravessada por temáticas curriculares discutidas em disciplinas educacionais $\left(\mathrm{P}_{3}\right.$, $\left.\mathrm{P}_{2}, \mathrm{P}_{8}, \mathrm{P}_{9}, \mathrm{P}_{11}\right)$ ou não $\left(\mathrm{P}_{1}, \mathrm{P}_{4}, \mathrm{P}_{5}, \mathrm{P}_{6}, \mathrm{P}_{7}, \mathrm{P}_{10}, \mathrm{P}_{12}, \mathrm{P}_{13}\right)$.

Podemos destacar três discursos representativos, veiculados e reiterados pelos Pibidianos, ao falar de currículos como documentos: "São documentos que norteiam aeducação" $\left(\mathrm{P}_{2}\right)$, "Planejamento de informações destinadas a conhecer algo" $\left(\mathrm{P}_{7}\right)$, "Processo descritivo dos passos que devem ser seguidos no processo de ensino" $\left(\mathbf{P}_{6}\right)$. Esta visão sobre os currículos comportaria o que Goodson (2008) trata como um currículo documental. Artefato instituído por ritos de validação de verdades, as quaisorganizam, analisam e legitimam os saberes dados como formativos, à medida que produzem fronteiras para delinear quais saberes não serão considerados como tal. Este processo de validação de documentos e regimentos que norteiam instituições permeiam a produção de regimes de verdades, que têm efeito de naturalizar coisas não naturais e atuam por meio de controles discursivos, no qual Foucault (2016; 2014) destaca: interdição, segregação e vontade da verdade. A visão de currículo como documento prescritivo coloca em circulação três mecanismos: delinear o que se pode ou não falar na escola; qual saber pertencerá ao âmbito escolar em detrimento de qual está segregado e destinado a outros espaços; e qual saber será eleito como verdadeiro, travestido nas tramas da verdade neutra, provinda de rigorosos métodos de produção, polimento e seleção.

Outro ponto de similitude consiste em considerar currículos como um conjunto de conteúdos: "Currículo seria o conteúdo programado para uma disciplina” $\left(\mathbf{P}_{8}\right)$, "Currículo é o que guia o ensino nas escolas, a base de conteúdos ofertadas" $\left(\mathrm{P}_{11}\right)$. Chamaríamos este ponto de um currículo das relações. Vemos uma tentativa de baliza em torno dos saberes eleitos como científicos, no ensino formativo, mas a resposta nos deixa um vazio: conteúdo seria uma palavra vazia. Vazio no sentido de Laclau (2011), por ser tão polissêmico a ponto de não ter um significado fixo, apriorístico. Dentro de uma 
disciplina e no ensino das escolas: existem gritos, rabiscos, conversas múltiplas, Netflix ${ }^{g}$, áudios, vídeos, imagens, WhatsApp ${ }^{t 0} \ldots$ Se Goodson (2008) trata este como um currículo das práticas escolares, preferimos como um currículo das relações, a fim de deixar fluir os múltiplos sentidos de currículos e conteúdos que podem adentrar no que é considerado formação destes sujeitos, no que toca a uma aproximação de olhar para o currículo, ciências e conteúdos como artefatos culturais, no vazio como espaço de criação.

Estes currículos, sejam documentos oficiais ou conjunto de conteúdos, agem como dispositivos, tocam as trajetórias de vida e constituições dos sujeitos, sempre pontuados como uma entidade sem rosto, sem autoria evidente nas falas dos Pibidianos. Todavia, $\left(\mathrm{P}_{1}\right.$ e $\left.\mathrm{P}_{9}\right)$ trazem à cena o currículo como uma prescrição de si, uma apresentação de seu projeto de vida constituinte, sua trajetória de vida narrada: "Currículo é um documento para apresentar o que cada um fez durante sua vida" $\left(\mathbf{P}_{9}\right)$, "É a descrição de suas informações" $\left(\mathbf{P}_{1}\right)$. Currículo aqui não como um testemunho do outro, mas como o próprio sujeito mostra seus constituintes que avalia como enunciáveis. É a possibilidade de revisitar-se em sua história e de produzir-se presentificando-a (VEIGA-NETO, 2009).

As questões de educação e ensino já aparecem quando o currículo é discutido pelos Pibidianos e é constantemente levantado pelos defensores e contrários ao PL EsP. Desta forma buscamos investigar, no que toca às visões sobre educação e ensino, evidenciando dois pontos de similitude: a) Os que veem educação e ensino como aspectos em comum, não separados e sem definições distintas $\left(\mathrm{P}_{4}, \mathrm{P}_{5}\right)$; b) Pibidianos que consideram educação como os processos culturais, sociais que produzem/formamvalores, moralidades e habilidades nos sujeitos e, ensino como uma correia de transmissão de conteúdos científicos, como um processo instrucional do conhecimento cumulado $\left(\mathrm{P}_{1}, \mathrm{P}_{2}, \mathrm{P}_{3}, \mathrm{P}_{6}, \mathrm{P}_{7}, \mathrm{P}_{8}, \mathrm{P}_{9}, \mathrm{P}_{10}, \mathrm{P}_{11}, \mathrm{P}_{12}, \mathrm{P}_{13}\right)$. Quando indagados sobre a possibilidade de alguma possível educação neutra, como prega o projeto EsP, apenas $\left(\mathrm{P}_{\mathrm{I}}\right)$ considera a possibilidade de neutralidade no processo educacional, sendo que $\left(\mathrm{P}_{5}\right)$ acredita não saber colocar sua opinião e os outros Pibidianos acreditam que é impossível uma educação neutra $\left(\mathrm{P}_{2}, \mathrm{P}_{3}, \mathrm{P}_{4}, \mathrm{P}_{6}, \mathrm{P}_{7}, \mathrm{P}_{8}, \mathrm{P}_{9}, \mathrm{P}_{10}, \mathrm{P}_{11}\right.$, $\mathrm{P}_{12}, \mathrm{P}_{13 .}$.

Os que não separavam educação e ensino traziam ponderações como: "Educar e ensinar consiste em favorecer meios para os alunos desenvolverem

\footnotetext{
${ }^{9}$ Site que disponibiliza conteúdos audiovisuais: séries, filmes, documentários.

${ }^{10}$ Aplicativo de smartphones utilizado para troca de mensagens, áudios, vídeos e imagens.
} 
senso crítico, o interesse pelas ciências, assim como desenvolver seu próprio conhecimento" $\left(\mathbf{P}_{4}\right)$, "Passar um conhecimento adiante e tornar uma pessoa cidadã, ensinando-a a respeitar diferenças etc.” $\left(\mathbf{P}_{s}\right)$. Contudo, a maioria dos Pibidianos apresentava concepções de educação e ensino em separata: "Educar é transportar valores éticos a outra pessoa [...] ensinar é passar algo para o outro daquilo que você tem conhecimento" $\left(\mathrm{P}_{\mathrm{I}}\right)$, "Educar seria ação de mostrar valores a uma pessoa [...] ensinar tem como objetivo levar o conhecimento científico a uma pessoa" $\left(\mathrm{P}_{8}\right)$, "Educar é passar um conjunto de hábitos e valores, enquanto ensinar seria o repasse de conhecimento" $\left(\mathbf{P}_{13}\right)$.

O que visualizamos é a ideia de ensino como correia de transmissão, como um repasse de um conjunto de conhecimentos historicamente acumulados que não sofre traduções nos processos de ensino e não produz valores, hábitos, éticas e moralidades. Um ensino bipartido de educação separada de ensino. Como gêmeos siameses essa tentativa de separação pode levar ambos ao óbito, sendo usada como substrato enunciativo que dá apoio a uma supressão das licenciaturas na nova reforma do Ensino Médio, realizada via Medida Provisória 746/2016 ${ }^{11}$ na substituição das licenciaturas pelo 'notório saber'. Evidencia-se na reforma um olhar de ensino apenas como transmissão, então é preciso apenas saber repeti-lo/transferi-lo. Se voltarmos nossos olhos às perspectivas curriculares e pedagógicas ensaiadas por Silva (2015), nem os currículos tradicionais consideravam que o ensino não produzisse, por mais técnicos e repetitivos que fossem, valores e habilidades.

Neste tocante, é interessante perguntarmo-nos: $O$ que seria um conhecimento a ser transferido? Apenas o conhecimento científico é do plano do ensinar, enquanto outros ficam na tutela da educação? Algumas dissonâncias passam a se evidenciar, de modo que todos os sujeitos que consideravam currículo como "um conjunto de conteúdo" $\left(\mathrm{P}_{3}, \mathrm{P}_{8}, \mathrm{P}_{11}, \mathrm{P}_{12}, \mathrm{P}_{13}\right)$ realizam a separação entre ensinar-educar, sendo que $\left(\mathrm{P}_{3}\right)$ e $\left(\mathrm{P}_{12}\right)$ justificam que o processo de ensino se dá apenas no interior da instituição escolar. Em contraponto, $\left(\mathrm{P}_{4}\right)$ e $\left(\mathrm{P}_{10}\right)$ que alinhavaram a ideia de currículo como prescrição documental de saberes, não faziam a dicotomia ensino-educação, vendo-os como integrantesde um mesmo processo, ao qual podemos chamar de pedagogias.

Com aportes em Foucault (2016, 2014, 2013, 2008, 2000), temos em mente que todo espaço é um espaço pedagógico, sendo que nas microfísicas das

O documento oficial da Medida Provisória 746/2017 encontra-se disponível em: <https://www25.senado.leg.br/web/atividade/materias/-/materia/126992>. Acesso em 7 de agosto de 2017. 
relações estão capilarizados saberes-poderes. O encontro de corpos gera afetos e percepções, que os constituem, reconstituem e os pedagogizam. A escola como instituição que pedagogiza os corpos tem uma regulamentação para a produção de corpos disciplinados, contudo esta não tem controle das pedagogias que circundam dentro de seus espaços. No interior das instituições estão em funcionamento tensões, fraturas, rasgos, linhas de fuga e surgimentos efêmeros de espaços que Foucault chamou de heterotópicos. O que o filósofo nos diz é que os controles discursivos atrelados a currículos, educação e ensino passam para além da interdição e segregação. Em outros termos, abre-se o espaço para criação e produção de novas e múltiplas possibilidades. No entanto, tem nos preocupado, e nos espanta, o ganho de força da "vontade de verdade", o que faz com que o discurso da neutralidade seja conclamado para a exclusão de outras discursividades.

Os Pibidianos participantes em sua maioria acreditam que a Escola não deva atender aos valores religiosos e morais de cada família, sinalizando que geraria uma exclusão de estudantes e limitaria a liberdade de aprender destes $\left(\mathrm{P}_{2}, \mathrm{P}_{3}, \mathrm{P}_{4}, \mathrm{P}_{5}, \mathrm{P}_{6}, \mathrm{P}_{7}, \mathrm{P}_{8}, \mathrm{P}_{9}, \mathrm{P}_{10}, \mathrm{P}_{11}, \mathrm{P}_{12}\right)$, enquanto $\left(\mathrm{P}_{1}\right)$ acredita que a escola deva atender aos valores familiares para que o estudante "não se sinta discriminado" e $\left(\mathrm{P}_{13}\right)$ acredita que a escola deva atender aos valores religiosos e morais de cada família, o que geraria um sentimento de "inclusão para todos os estudantes".

Grande discussão em torno da moralidade familiar no processo educativo é a restrição da liberdade de ensinar e da liberdade de aprender, de modo que o processo de ensino e de aprendizagem encontrar-se-ia sob tutela e cerceamento da crença pessoal dos pais (CARVALHO; POLIZEL; MAIO, 2017; PENNA, 2017; MATTOS et al., 2017; RATIER, 2016; CARA, 2016; XIMENES, 2016).

\section{PERCEPÇÕES SOBRE O PROJETO ESP E SEUS EFEITOS}

No que toca a compreensão dos Pibidianos sobre currículo, educação e ensino, voltamo-nos ao nosso segundo ponto de interesse: "Quais as percepções dos Pibidianos de Ciências e Biologia sobre o projeto EsP e seus efeitos?”.

Evidenciamos quatro pontos de similitude sobre como estes olhavam para o PL: a) o PL como um projeto de interdição, censura e amordaçamento do professor, a tecnologia do silenciamento $\left(\mathrm{P}_{3}, \mathrm{P}_{4}, \mathrm{P}_{5}, \mathrm{P}_{8}, \mathrm{P}_{10}, \mathrm{P}_{11}\right)$; b) o projeto como apagador de conteúdos programáticos de disciplinas, proibindo-os via 
exclusão curricular $\left(\mathrm{P}_{2}, \mathrm{P}_{7}, \mathrm{P}_{12}\right)$; c) o projeto como uma abertura para os saberes dos estudantes, via não coerção destes pelos docentes $\left.\left(\mathrm{P}_{13}\right) ; \mathrm{d}\right) \mathrm{o}$ projeto como uma política de não incitação do alunado a posicionamentos políticos $\left(\mathrm{P}_{9}\right) ;\left(\mathrm{P}_{6}\right) \mathrm{e}$ $\left(\mathrm{P}_{1}\right)$ deixaram a questão em branco. Neste ponto, o participante $\left(\mathrm{P}_{1}\right)$ passa a abster-se de responder às questões.

Esses pontos de similitude encontram-se interligados, todavia referem-se a diferentes sujeitos:um fala do professor, um do currículo e dois pontos são destinados ao estudante. Ao falar do professor as falas voltam-se à interdição e censura do mesmo, esta imagem é veiculada tanto pelo (anti)movimento escola sem partido quanto pelo grupo de professores contra o(anti)movimentoEscola sem Partido, o de "não poder falar sobre teorias e dar opiniões sobre o assunto" $\left(\mathrm{P}_{5}\right)$, uma liberdade de ensinar que é restringida pelo processo de interdição discursiva. A imagem do professor é instituída como um mal a ser combatido, vigiado, um possível perturbador da ordem e corruptor da inocência ou, um sujeito que possui conhecimento e convicções, mas é calado, não consegue emancipar seus pupilos - ambos os discursos elegem um demônio a ser exorcizado e um messias a ser sacralizado (CARVALHO; POLIZEL; MAIO, 2017; PENNA, 2017; PENNA, 2016). O currículo é dissecado e tem seus conteúdos retirados e segregados para espaços outros, é a exclusão discursiva via segregação como corrobora Foucault (2016; 2014; 2008; 2000). E dá ao estudante, uma noção de seguridade social, que não é "incitadapoliticamente" $\left(\mathrm{P}_{9}\right)$.tendo uma abertura à diversidade de conhecimentos, pois "o professor não prejudicará nem favorecerá” alunos e assim circulará uma diversidade de opiniões, mesmo que seja retirado seu direito de contato com determinados conteúdos. A legislação assim é um processo de retirada e censura via política da negação a professores e ao currículo e, de garantia aos estudantes, segundo os pontos de similitude evidenciados.

Compreendemos que o PL ainda não foi aprovado em nível nacional, contudo reconhecemos que o mesmo já apresenta efeitos no espaço escolar, de modo que vislumbramos nos discursos dos Pibidianos quatro pontos de similitude em suas falas: a) o PL tem efeito sobre a interdição do docente, dos conteúdos e das singularidades do ser professor via dogmas e ideologias $\left(\mathbf{P}_{3}, \mathbf{P}_{4}\right.$, $\left.\mathrm{P}_{10}, \mathrm{P}_{11}, \mathrm{P}_{12}\right)$; b) a retirada de censo crítico e do direito ao saber múltiplo pelos estudantes, via censura da "moralidade familiar" $\left.\left(\mathbf{P}_{2}, \mathbf{P}_{7}, \mathbf{P}_{8}, \mathbf{P}_{9}\right) ; \quad c\right)$ a desestruturação das matérias ocasionando a perda de sentidos destas $\left(\mathbf{P}_{5}\right)$; e, d) o PL tem proporcionado o domínio mais amplo do conteúdo, visto a não censura dos estudantes por parte dos docentes $\left(\mathrm{P}_{13}\right) ;\left(\mathrm{P}_{6}\right)$ e $\left(\mathrm{P}_{1}\right)$ deixaram a questão em branco. 
Novamente vemos no projeto uma política da negação, de modo que os efeitos atuais consistem na coerção e interdição de docentes, bem como conteúdos e singularidades dos modos de ser, visto que "professores ficariam limitados na sala de aula" $\left(\mathrm{P}_{10}\right)$ e os "conteúdos não seriam trabalhados [...] por restrições da religião” $\left(\mathbf{P}_{11}\right)$. As alterações pedagógicas se transformariam radicalmente, de modo que "muitos conteúdos que falam sobre políticas e religião provavelmente seriam cortados" $\left(\mathrm{P}_{9}\right)$ e os alunos passariam a ter uma "ausência de pensamento crítico e de conteúdos" $\left(\mathrm{P}_{7}\right)$. O que evidenciamos é mais uma vez as políticas de interdição e segregação atuantes no projeto para a exclusão de discursos. Estas interdições levam até mesmo a uma "desestruturação de toda a matéria" $\left(\mathrm{P}_{5}\right)$ de Biologia, de modo que essa se funda sob o viés da origem da vida, biologia comparada e do evolucionismo ${ }^{12}$ (FOUCAULT, 2008; 2000), temas que se encontram sob o risco de censura. Todavia, $\left(\mathrm{P}_{13}\right)$ vê que o projeto tem gerado ampliação nos conhecimentos dos estudantes, visto a não censura destes pelo professor.

No que toca aos temas identificados como ameaçados no ensino de Ciências e Biologia, os sujeitos demarcam: a) evolução e darwinismo $\left(\mathrm{P}_{3}, \mathrm{P}_{6}, \mathrm{P}_{8}\right.$, $\left.\mathbf{P}_{9}, \mathbf{P}_{10}\right)$; b) discussões de gênero e sexualidade $\left.\left(\mathbf{P}_{3}, \mathbf{P}_{8}, \mathbf{P}_{10}\right) ; c\right)$ origem da vida $\left(\mathbf{P}_{11}\right)$; d) ditadura $\left(\mathrm{P}_{3}\right)$; e, e) economia $\left(\mathrm{P}_{3}\right)$.

Acredita-se na proibição destes temas visto a origem do (anti)movimento EsP, como declarado pelo próprio idealizador do projeto, sendo: a) inspiradono programa privado norte-americanoNo Indocrination, que surge da organização de pais que denunciam ações pedagógicas tendenciosas e incentivam as denúncias públicas de professores, tendo como pauta a maneira que são ensinadas temáticas como racismo - de brancos contra negros - e professores considerados pró-islâmicos; b) semelhança com a iniciativa organizada pelo Creation Studies Institute que combate a suposta Indocrination nas escolas públicas, relacionadas ao ensino de evolução; e, c) aos (anti)movimentos contra o ensino de gênero e sexualidade, organizados por vertentes da igreja católica e apropriados por vertentes evangélicas neofundamentalistas sob o sintagma da "ideologia de gênero" e que se difundem no Brasil como bandeira do (anti)movimento EsP e da bancada cristã - que também apropriam-se dos discursos revisionistas sobre a ditadura militar e contra o marxismo (ESPINOSA; QUEIROZ, 2017).

\footnotetext{
${ }^{12}$ Consideramos que o pensamento científico-epistemológico também opera via interdição, segregação e vontade de verdade, todavia apontamos que a disciplina de Ciências e Biologia funda-se nestes eixos que apresentar-se-ão vulneráveis à censura via PL.
} 
Para além do apoio popular de massas, o Projeto de Lei referente ao EsP busca firmar-se em âmbito legislativo e judiciário fazendo alterações significativas na LDB. Os Pibidianos apontam que: a) O PL nos moldes atuais são incompatíveis com a LDB, bem como toca na rescisão de direitos garantidos na constituição $\left(\mathrm{P}_{2}, \mathrm{P}_{3}, \mathrm{P}_{4}, \mathrm{P}_{6}, \mathrm{P}_{7}, \mathrm{P}_{8}, \mathrm{P}_{10}, \mathrm{P}_{11}, \mathrm{P}_{12}\right)$; b) a $\mathrm{PL}$ atende aos princípios da $\mathrm{LDB}\left(\mathrm{P}_{9}, \mathrm{P}_{13}\right)$; e, c) atende parcialmente os princípios da LDB $\left(\mathrm{P}_{5}\right)$; $\left(\mathbf{P}_{1}\right)$ deixou a questão em branco.

As similitudes dos discursos que consideram incompatíveis as proposições do EsP com a LDB pontuam dois principais itens, sendo: a) "não permite formar um aluno cidadão" $\left(\mathrm{P}_{4}\right)$, compreendendo um cidadão por aquele que tem senso crítico, que pensa, fala, se coloca e reconhece educação, espaços e modos de ser como campos políticos; e, b) "interfere demaneira negativa na liberdade de ensinar do professor, e também na visão de escola atual, que permite criar diálogos entre professor e aluno" $\left(\mathrm{P}_{3}\right)$. Discursos alinhados à preocupação de uma escola democrática (PENNA, 2017; 2016). Todavia, a discursividade dos que acreditam que a proposta adequa-se à LDB aponta para o discurso de que "se o princípio da LDB é que todos tenham os mesmos direitos é possível que a escola sem partido atenda estes princípios, pois não excluiria ninguém [...] trataria da mesma forma” $\left(\mathrm{P}_{9}\right)$.

Contudo, percebe-se que a PL não aponta para preocupações com relação ao atendimento ou não de sua proposta à $\mathrm{LDB}$, mas sim para a alteração e inserção de ementas na LDB para que ela se adeque ao projeto. Fernando Penna (2017) nos aponta para modificações significativas nos documentos oficiais, estabelecendo um comparativo das alterações caso o projeto seja aprovado:

O segundo princípio proposto pelo programa Escola sem Partido é o "pluralismo de ideias no ambiente acadêmico". Como aparece na nossa Constituição? Na Constituição Federal, artigo 206, inciso III: "pluralismo de ideias e de concepções pedagógicas, e coexistências de instituições públicas e privadas de ensino".

O terceiro princípio estabelecido no Projeto de Lei: “A liberdade de aprender como projeção específica no campo da educação da liberdade de consciência". Como aparece na nossa Constituição? Inciso II, do artigo 206: "Liberdade de aprender, ensinar, pesquisar, divulgar o pensamento, a arte e o saber" (PENNA, 2017. p. 41). 
Assim é evidente que a adequação dos documentos oficiais volta-se a um processo de apagamentos, no que concerne a: concepções pedagógicas e liberdades de ensinar, pesquisar, divulgar o pensamento, a arte e o saber. $\mathrm{O}$ que se mantém atuando é a pedagogia da negação. Outro aspecto de choque, no que se refere aos documentos oficiais, é a LDB, nos moldes atuais, pautar-se em uma educaçãobaseada em princípios éticos educativos e o (anti)movimento EsP pauta-se na moralidade familiar e religiosa.

Pretende-se que estas alterações sejam realizadas nos documentos oficiais de modo que afetarão diretamente as questões de identidade, diferenças e diversidade no espaço escolar ${ }^{13}$. Os Pibidianos apontam para os seguintes pontos de similitude: a) os efeitos tocarão na exclusão social, padronização dos sujeitos e na retirada de liberdade de escolhas e de ser do sujeito no espaço escolar, de maneira que estarão submetidos a coerção, perseguição e normalização $\left.\left(\mathrm{P}_{2}, \mathrm{P}_{3}, \mathrm{P}_{5}, \mathrm{P}_{9}, \mathrm{P}_{12}\right) ; \mathrm{b}\right)$ os efeitos tocarão na falta de conhecimento sobre a história dos movimentos sociais, das questões populares e um regresso a um totalitarismo $\left(\mathrm{P}_{4}, \mathrm{P}_{8}, \mathrm{P}_{10}, \mathrm{P}_{11}\right)$; c) não sabe-se opinar sobre os efeitos $\left.\left(\mathrm{P}_{6}, \mathrm{P}_{7}\right) ; \mathrm{d}\right)$ possui uma crença na inclusão dos alunos, visto que o apartidarismo sanaria a problemática das diferenças $\left(\mathrm{P}_{13}\right) ;\left(\mathrm{P}_{1}\right)$ deixou a questão em branco.

Assim, $\left(\mathrm{P}_{2}\right)$ pontua que a possibilidade de um "apagamento de todas as identidades, diversidade e diferenças [...] educar seria normatizar”, não que estas parariam de existir, mas que não seriam registradas nos documentos do âmbito escolar, "todos se tornariam cada vez mais parecidos" $\left(\mathbf{P}_{9}\right)$. As identidades e diferenças seriam afetadas pela falta de consciência histórica, "a falta de conhecimento da diversidade [...] de conteúdos que vão contra os interesses da 'igreja”" $\left(\mathrm{P}_{8}\right)$, “todas as lutas que pertencem à ordem política na história não seriam abordadas" $\left(\mathrm{P}_{4}\right)$. Dois olhares que se encontram no que Arroyo (2015) chama de uma falta de conhecimento de si, uma possibilidade de compreender sua própria constituição como sujeito histórico, como é visto também em outras teorias (pós)críticas dos currículos e educação (SILVA, 2015; GOODSON, 2008). Uma perda de identidade histórica que o constitui

\footnotetext{
${ }^{13}$ Não voltamo-nos à discussão da inconstitucionalidade do projeto visto que: a) Othoniel Pinheiro Neto levanta na Revista Jus os 10 pontos de inconstitucionalidade do projeto, disponível em: <https://jus.com.br/artigos/46182/as-multiplas-inconstitucionalidades-e-equivocos-dos-projetos-de-lei-escolasem-partido> - Acesso em 12 de agosto de 2017; e, b) Visto um alinhamento com a perspectiva de Giorgio Agamben (RAMOS, 2017), de que em estados de exceção instauram-se ditaduras comissárias, que suprimem a constituição para validar sua existência, produzindo assim possibilidade de surgimento de uma ditadura soberana, que implementa sua decisão como nova constituinte - assim vemos a possibilidade de aprovação do projeto sob um estado de ditadura comissária e sua manutenção de validação em uma ditadura soberana.
} 
como sujeito e o permite afirmar-se diferente do outro em espaçosregulados por normativas de poder. Todavia, $\left(\mathrm{P}_{13}\right)$ acredita que isto não aconteceria, e que na verdade "o Projeto de Lei influenciará na inclusão de alunos, na não discriminação”. Tem-se a impressão nesta fala que o problema da discriminação é produzido pelas opiniões do professorado e, se este não puder se posicionar, a escola encontra-se liberta do mal-estar das desigualdades. Contudo, trabalhos como os presentes na obraTensões no espaço escolar: violência, bullying, indisciplina e homofobia, uma coletânea de artigos organizados pela professora Ivana Veraldo (2014), têm mostrado a necessidade de mais professores trabalharem temáticas de identidade e diferença para minimizar os efeitos discriminatórios.

Presenciamos multiplicidades de discursos veiculados pelos Pibidianos, que apresentam pontos de similitude em dado momento de coleta-análise, contudo ficamos instigados com os discursos de $\left(\mathrm{P}_{13}\right)$, que nos possibilita pensar a relação religião $\mathrm{x}$ apoio ao projeto $^{14}$.

\section{CONSIDERAÇÕES FINAIS}

Nas atuais contingências do cenário brasileiro, tem-se levantado os conclames por reformas educacionais e as críticas a legalidade e legitimidade dos modus que estas são realizadas. Dentre elas, demarca-se o avanço do Projeto de Lei Escola sem Partido que tem ganhado força e apoio no congresso e também questionada no que diz respeito à sua (in)constitucionalidade e seus efeitos de criminalização da prática docente. É nesta eventualidade que nos colocamos a investigar quais as percepções sobre integrantes de um projeto de incentivo à docência - o programa Pibid - sobre as questões curriculares, de educação, de ensino e referentes ao projeto EsP. Evidenciamos que as concepções sobre currículos perpassaram sobre este ser: a) considerado um documento prescritivo de organização e planejamento que norteia o processo educacional nos espaços escolares; b) um conjunto de conteúdos organizados que guiam o processo formativo; e, c) uma possibilidade de narrar a si. Os

\footnotetext{
${ }^{14}$ Reconhecemos um alinhamento do caráter religioso no atravessar da subjetivação e da veiculação discursiva desta Pibidiana, vendo a necessidade de demarcar a relação religião e o apoiar do projeto (refletido até mesmo na representação do mesmo no cenário legislativo, como supracitado). Todavia, para maiores explanações sobre a construção de tal discursividade e de quais os discursos e dispositivos atravessam a Pibidiana, faz-se necessário outras intervenções como estas. Sendo assim, indicamos este ponto como uma percepção visualizada na investigação.
} 
Pibidianos consideram a) ensino e educação aspectos inseparáveis e b) a dicotomia ensino e educação como aspectos distintos (podendo ou não estar interligado) sendo: educação atreladas ao processo de produção de valores, habilidades e culturas e o ensino como um processo de transmissão de conhecimentos.

No que se refere as percepções enunciadas, estas conspiram para uma impossibilidade de neutralidade no processo educacional e as educações escolares como um processo que não deve atender aos valores morais, religiosos e familiares de cada estudante. Compreende-se que tais valores adentram e atravessam a escola e o processo formativo, todavia estes não devem ser base para a organização do processo educacional e produção de documentos oficiais. Os efeitos do (anti)movimento EsP e do Projeto de Lei permeiam: a) uma interdição dos docentes e de suas singularidades sob argumentos de dogmas e ideologias religiosas; b) a retirada de senso crítico e do direito ao saber dos estudantes; c) desestruturação de disciplinas visto a retirada de conteúdos bases que deixaram-nas esvaziadas de sentido; e, d) uma possibilidade de domínio mais amplo do conteúdo visto o não cerceamento docente.

Os Pibidianos se dividem ao que toca o Projeto de Lei atender ou não a LDB, contudo o projeto não pretende atender à Lei de Diretrizes e Bases da educação, mas sim alterá-la para que ela atenda às suas proposições.O projeto promove efeitos diretamente nas questões de identidade, diferença e desigualdades, sendo: a) A retirada de liberdade de ser e escolher do sujeito, bem como uma manutenção da exclusão social e da padronização dos sujeitos; b) Ignora a consciência de si nos currículos efetuando uma assepsia histórica de conquistas e trações dos movimentos sociais; e, c) Uma crença na inclusão de alunos pelo sanar da problemática da discriminação e desigualdade.

Compreendemos que tais analíticas discursivas que levaram ao estabelecimento destes pontos de similitudes consistem em um movimento inicial no registrar destas percepções. Haja vista o cenário político, econômico e educacional encontrar-se em um momento instável, no qual sob o discurso da crise e agenciamento das velocidades nos trâmites 'democráticos' as medidas mais hediondas são e podem ser tomadas. Assim, tais percepções são um primeiro percurso que capturamos nesta escrita, mas outras discursividades encontram-se em circulação e precisam ser cartografadas. 


\section{REFERÊNCIAS}

ARROYO, M.G. Movimentos sociais e a construção de outros currículos. Educar em Revista,n. 55, 2015, p. 47-68.

CAPES. Coordenação de Aperfeiçoamento de Pessoal de Nível Superior. Programa Institucional de Bolsa de Iniciação Científica - PIBID. Disponível em: 〈http://www.capes.gov.br/educacao-basica/capespibid>. Acesso em: 23 jul. 2018.

CARA, D. O programa "Escola sem Partido" quer uma escola sem educação. In: AÇÃO EDUCATIVA (Org.). A ideologia do movimento Escola sem Partido: 20 autores desmontam o discurso. São Paulo: Ação Educativa, 2016, p. 43-47.

CARVALHO, F.A.; POLIZEL, A.L.; MAIO, E.R. Uma escola sem partido: discursividade, currículos e movimentos sociais. Rev. Semina: Ciências sociais e humanas, v. 37, n. 2, 2017, p. 193-210.

ESPINOSA, B.R.S.; QUEIROZ, F.B.C. Breve análise sobre as redes do Escola sem Partido. In: FRIGOTTO, G. (Org.). Escola "sem" Partido:esfinge que ameaça a educação e a sociedade brasileira. Rio de Janeiro: LPP/UERJ, 2017, p. $49-62$.

FONSECA, C. Quando cada caso não é um caso: pesquisa etnográfica e educação. Revista Brasileira de Educação.jan./fev./mar./abr., n. 10, 1999.

FOUCAULT, M. A ordem do discurso.aula inaugural do Collège de France, pronunciada em 2 de dezembro de 1970. 24. ed. São Paulo: Editora Loyola, 2014.

2008.

Arqueologia do saber. 7. ed. Rio de Janeiro: Forense Universitária,

. As palavras e as coisas: uma arqueologia das ciências humanas. 8. ed.

São Paulo: Martins Fontes, 2000.

. Microfísica do Poder.4. ed. Rio de Janeiro: Paz e Terra, 2016.

. "O corpo utópico": Em O corpo utópico, as heterotopias, por Michel

Foucault. São Paulo: N-1, 2013.

GOODSON, I.Currículo: teoria e história. 8. ed. Petrópolis-RJ: Vozes, 2008. 
LACLAU, E. Emancipação e diferença. Rio de Janeiro: EdUERJ, 2011.

MATTOS, A.; MAGALDI, A.M.B.M.; COSTA, C.M.; SILVA, C.F.S.; VELLOSO, L.; LEONARD, P.; ALBERTI, V.; PENNA, F.A.. Educação e liberdade: apontamentos para um bom combate ao Projeto de Lei Escola sem Partido. In: FRIGOTTO, G. (Org.). Escola "sem" Partido: esfinge que ameaça a educação e a sociedade brasileira. Rio de Janeiro: LPP/UERJ, 2017, p. 87104.

PENNA, F.A. O Escola sem Partido como chave de leitura do fenômeno educacional. In: FRIGOTTO, G.(Org.). Escola "sem" Partido: esfinge que ameaça a educação e a sociedade brasileira. Rio de Janeiro: LPP/UERJ, 2017, p. $35-48$.

O ódio aos professores. In: AÇÃO EDUCATIVA (Org.). A ideologia do movimento Escola sem Partido: 20 autores desmontam o discurso. São Paulo: Ação Educativa, 2016, p. 93-100.

RAMOS, M.N. Escola sem partido: a criminalização do trabalho pedagógico. In: FRIGOTTO, G.(Org.). Escola "sem" Partido: esfinge que ameaça a educação e a sociedade brasileira. Rio de Janeiro: LPP/UERJ, 2017, p. 75-86.

RATIER, R. 14 Perguntas e respostas sobre o "Escola sem Partido". In: AÇÃO EDUCATIVA (Org.). A ideologia do movimento Escola sem Partido: 20 autores desmontam o discurso. São Paulo: Ação Educativa, 2016, p. 30-42.

RIVELINI-SILVA, A.C.; OLIVEIRA, M.A. Ser professor no Pibid: espaços e dispositivos de formação. In: XVIII Anais do Encontro Nacional de Ensino de Química, Universidade Federal de Santa Catarina, Florianópolis, 2016, p. 1-10. Disponível em: 〈http://www.eneq2016.ufsc.br/anais/resumos/R0749-1.pdf〉. Acesso em: 23 jul. 2018.

SILVA, T.T. Documentos de identidade: uma introdução às teorias do currículo. 3. ed. Belo Horizonte: Autêntica, 2015.

VEIGA-NETO, A. O currículo e seus três adversários: os funcionários da verdade, os técnicos do desejo, o fascismo. In: RAGO, Margareth; VEIGANETO, Alfredo. Para uma vida não fascista. Belo Horizonte: Autêntica, 2009, p. 19-26.

VERALDO, I. Tensões no espaço escolar: violência, bullying, indisciplina e homofobia. Maringá: Eduem, 2014. 
XIMENES, S. O que o direito à educação tem a dizer sobre "Escola sem Partido"? In: AÇÃO EDUCATIVA (Org.). A ideologia do movimento Escola sem Partido: 20 autores desmontam o discurso. São Paulo: Ação Educativa, 2016, p. 49-58.

Recebido em 19/11/2018

Aprovado em 13/02/2019 